\title{
TANGGAP PERTUMBUHAN AREN (Arenga pinnata (Wurmb) Merr.) DIINOKULASI DENGAN FUNGI MIKORIZA ARBUSKULA DAN PENGAPURAN DI LAHAN PASCA TAMBANG BATUBARA
}

\author{
Growth Responses of Sugar Palm (Arenga pinnata (Wurmb) Merr.) Inoculated with \\ Arbuscular Mycorrhizal Fungi and Liming Application on the Coal Post-mining Land
}

Maria Paulina $^{1^{*}}$, Irdika Mansur $^{2}$, dan Ahmad Junaedi ${ }^{3}$

(Diterima Agustus 2017/Disetujui Oktober 2017)

\begin{abstract}
Sugar palm is one of local plants spesies that may potential for reclamation program because can be planted under the stands of forest crops. Forest crops can be shade seedlings sugar palm from direct sunlight because the growth of sugar palm is relatively slow. Sugar palm can be useful even without cutting down the trees. Previously, sugar palm had been planted at PT Berau Coal and had produced fruit. The research was conducted at coal post-mining land of PT Bukit Asam, Tanjung Enim, South Sumatera. The research using combination of AMF and liming treatment is as follows, ie MaKO (control), Makl (seedling with AMF without inoculation; liming $30 \mathrm{~g} \mathrm{plant}^{-1}$ ), MiKO (AMF indigenous seedling inoculation; without liming), MiK2 (AMF indigenous seedling inoculation, liming $60 \mathrm{~g}_{\text {plant }}^{-1}$ ), MmKO (AMF mycofer seedling inoculation; without liming), and MmK3 (AMF mycofer seedling inoculation, liming $120 \mathrm{~g}_{\text {plant }}^{-1}$ ). The results showed that sugar palm could be grown in the coal post-mining land. The combination of AMF and liming treatment did not significant effect on observed variables of plant height, rachis length, diameter, leaves number, number of spore and root cholonization. Sugar palm seedlings that have been infected with AMF could be grown and provide a good growth response even without liming.
\end{abstract}

Keywords : Arbuscular Mycorrhizal Fungi (AMF), marginal land, sugar palm

\section{PENDAHULUAN}

Mikoriza adalah hubungan simbiosis mutualisme antara fungi dan akar tanaman yang saling menguntungkan, dimana fungi mendapatkan senyawa karbon hasil fotosintesis dari tanaman inang, sedangkan tanaman inang mendapat pasokan unsur hara dari fungi (Smith \& Read 2008). Fungi Mikoriza Arbuskula (FMA) merupakan fungi yang bersimbiosis dengan perakaran tanaman yang berperan sebagai bioprosesor dengan menyerap air dan hara yang jauh dari jangkauan rambut akar, sebagai bioprotektor untuk melindungi tanaman dari cekaman biotika, sebagai bioaktivator untuk membantu menyimpan karbon di rhizosfer supaya meningkat, dan sebagai bioagregator untk meningkatkan agregasi tanah (Nusantara et al. 2012).

Menurut Setiadi dan Setiawan (2011), FMA merupakan pupuk hayati yang tidak mencemari lingkungan, pengaplikasiannya sangat efektif dan efisien. Sifat FMA dapat terus menerus tumbuh dan berkembang karena merupakan makhluk hidup,

\footnotetext{
${ }^{1}$ Mahasiswa Pascasarjana PS. Silvikultur Tropika,

Fakultas Kehutanan IPB

* Penulis korespondensi:

e-mail: paulinalyanouris@gmail.com

${ }^{2}$ Staff Pengajar Dept. Silvikultur, Fakultas

Kehutanan IPB

${ }^{3}$ Staff Pengajar Dept. Agronomi dan Hortikultura, Fakultas Pertanian IPB
}

sehingga pemberian FMA cukup sekali saja digunakan. Hasil penelitian Suharno dan Sancayaningsih (2013) menyebutkan bahwa FMA mampu untuk meningkatkan pertahanan tumbuhan pada lahan marginal dan FMA juga sebagai alternatif dalam meningkatkan peran berbagai jenis tumbuhan untuk revegetasi lahan tambang.

Sektor usaha kegiatan pertambangan batubara memberikan sumbangan besar bagi pendapatan negara. Perkembangan reklamasi lahan bekas tambang di Indonesia dibagi menjadi 3 yaitu sebelum tahun 1990, periode tahun 1990 sampai 2000 dan setelah tahun 2000. Sebelum tahun 1990, masih banyak perusahaan yang belum melakukan kegiatan reklamasi. Usaha reklamasi mulai dilakukan dengan penanaman Legum Cover Crop (LCC) dan jenis pohon yang cepat tumbuh di periode tahun 1990-2000. Setelah tahun 2000, barulah jenis-jenis tanaman lokal ditanam menjadi tanaman pengayaan di bawah tanaman kehutanan (Mansur 2010). Menurut Hermawan (2002), ketidaksuburan lahan bekas tambang karena timbunan dari lapisan bawah tanah dan terdapat lalu lintas dari alat-alat berat pada proses kegiatan penambangan dan penimbunan, sehingga menyebabkan penutupan poripori tanah serta padatnya lapisan tanah permukaan.

Amelioran merupakan bahan yang mampu memperbaiki kondisi fisik atau kesuburan tanah. Selain kompos, amelioran juga dapat berupa pengapuran. Lahan pasca tambang cenderung memiliki tanah yang 
masam (pH rendah), karena itu perlu upaya pengapuran untuk menaikkan $\mathrm{pH}$. Menurut Wicaksono dan Mansur (2014), perlakuan dengan pupuk kandang dan kapur pada akhir penelitian di areal bekas tambang mendekati $\mathrm{pH}$ normal (6.5) dan rata-rata pertumbuhan diameter jabon sebesar $7.3 \mathrm{~mm}$ per $25 \mathrm{ming} g u$.

Salah satu jenis tanaman lokal yang dapat digunakan sebagai tanaman pengayaan di lahan pasca tambang adalah aren (Arenga pinnata (Wurmb) Merr.). Tanaman aren dapat menjadi tanaman sisipan karena tanaman aren tidak harus ditebang untuk diambil manfaatnya. Adapun produk yang dihasilkan aren bukan kayunya, melainkan nira yang dapat diolah menjadi gula semut, gula kristal, gula cetak, alkohol, dan asam cuka, kolangkaling, ijuk, dan tepung aren (Akuba 2004).

Menurut Mariati (2013), pengembangan tanaman aren memiliki peluang yang besar karena tanaman aren dapat beradaptasi dengan berbagai tipe tanah, lahan kritis, dan padang alang-alang. Peraturan Menteri Pertanian (2014) menyatakan bahwa tanaman aren dapat tumbuh pada tanah-tanah liat, berpasir dan dapat tumbuh pada ketinggian 0 sampai 1400 meter di atas permukaan laut. Tanaman aren juga berpeluang sebagai penghasil etanol sebesar 1.43 juta KL bioetanol per tahun (Effendi 2010).

Penelitian ini bertujuan untuk: (1) menguji kemampuan bibit aren tumbuh di lahan pasca tambang dan (2) mengevaluasi pertumbuhan bibit aren dengan perlakuan kombinasi FMA dan pengapuran di lahan pasca tambang.

\section{METODE PENELITIAN}

\section{Tempat dan Waktu}

Penelitian dilaksanakan pada bulan November 2016 sampai dengan April 2017. Penanaman aren dilaksanakan di lahan pasca tambang batubara PT Bukit Asam (PTBA), Tanjung Enim, Sumatra Selatan. Analisis tanah dan kompos dilakukan di Laboratorium Batubara PTBA, sedangkan analisis tipe spora dan kolonisasi FMA dilakukan di Laboratorium Silvikultur SEAMEO BIOTROP.

\section{Bahan dan Alat}

Bahan yang digunakan dalam penelitian ini yaitu bibit aren (Arenga pinnata) yang sebelumnya telah diinokulasi mikoriza berumur 22 bulan, kompos tandan kosong kelapa sawit (TKKS) yang diperoleh dari PT Bumi Sawindo Permai (BSP), kapur pertanian (kaptan), aquades, larutan glukosa $60 \%$, larutan $\mathrm{KOH} 10 \%, \mathrm{HCl}$ $2 \%$, glyserin, polyvynil alkohol lactogliserol (PVLG), trypan blue dan larutan Melzer. Peralatan yang digunakan adalah alat ukur (meteran), paranet $75 \%$, jangka sorong, saringan bertingkat 4 yang berukuran $425 \mu \mathrm{m}, 212 \mu \mathrm{m}, 106 \mu \mathrm{m}$ dan $63 \mu \mathrm{m}$, mikroskop binokuler Olympus CX-21, tabung sentrifuse, sentrifuse, pinset spora, timbangan, cawan petri, pipet tetes, kaca penutup, kaca preparat, kamera, kertas label, tali rafia, kalkulator, perlengkapan alat tulis dan alat pertanian.

\section{Rancangan Percobaan}

Rancangan percobaan yang digunakan adalah Rancangan Acak Lengkap (RAL) dengan faktor tunggal berupa perlakuan kombinasi FMA dan pengapuran. Perlakuan kombinasi FMA dan pengapuran sebagai berikut, yaitu MaK0 (kontrol), MaK1 (bibit bermikoriza tanpa diinokulasi; pengapuran $30 \mathrm{~g} \operatorname{tanaman}^{-1}$ ), MiK0 (bibit inokulasi FMA indigenous; tanpa pengapuran), MiK2 (bibit inokulasi FMA indigenous; pengapuran 60 g tanaman ${ }^{-1}$ ), MmK0 (bibit inokulasi FMA mycofer; tanpa pengapuran), dan MmK3 (bibit inokulasi FMA mycofer; pengapuran $120 \mathrm{~g} \operatorname{tanaman}^{-1}$ ). Terdapat 6 perlakuan kombinasi FMA dan pengapuran yang diulang sebanyak 4 ulangan sehingga diperoleh 24 satuan percobaan. Setiap satuan percobaan terdapat 3 tanaman sehingga terdapat 72 tanaman. Pengamatan di lapangan dilakukan setaip 3 minggu sekali selama 4 kali. Model rancangan percobaan yang digunakan untuk percobaan tersebut adalah sebagai berikut:

$$
Y i i j=\mu+\alpha i+\varepsilon i j
$$

\section{Keterangan :}

$\mathrm{Y}_{\mathrm{ij}}=$ nilai respon dari perlakuan kombinasi FMA dan pengapuran ke-i; dan ulangan ke-j

$\mu \quad=$ nilai rata-rata

$\alpha \mathrm{i}=$ pengaruh perlakuan kombinasi FMA dan pengapuran ke-i

$\varepsilon_{\mathrm{ij}}=$ pengaruh acak pada perlakuan kombinasi FMA dan pengapuran ke-i, dan ulangan ke-j

\section{Analisis data}

Pengolahan data dilakukan dengan menggunakan ANOVA pada taraf $\alpha 5 \%$. Apabila hasil sidik ragam berpengaruh nyata, maka dilakukan pengujian dengan uji DMRT (Duncan Multiple Range Test) pada taraf $\alpha$ $5 \%$. Pengolahan data menggunakan program SAS Windows 9.1.3.

\section{Persiapan tanaman}

Tanaman yang digunakan adalah bibit aren berumur 22 bulan. Bibit aren diperoleh dari hasil penelitian Miska (2015) yang terdapat di lokasi pembibitan SEAMEO BIOTROP. Bibit aren dikemas supaya tidak mengalami kerusakan ketika proses pengangkutannya ke Tanjung Enim, Sumatera Selatan. Bagian pelepah daun bibit aren dibungkus dengan plastik bening dan diberi sedikit rongga, sedangkan pada bagian polibag diikat menggunakan lakban supaya tanah tidak berhamburan keluar. Bibit tersebut dibawa ke lokasi pembibitan PTBA dengan menggunakan truk. Bibit aren yang sudah tiba selanjutnya diaklimatisasi selama 2 minggu sebelum ditanam di lahan pasca tambang batubara.

\section{Persiapan lahan untuk penanaman}

Pemasangan ajir dilakukan setelah diketahui lokasi penanamannya dengan jarak tanam aren yaitu $8 \mathrm{~m} \times 8$ m. Pembuatan lubang tanam untuk bibit aren dengan ukuran $40 \mathrm{~cm}$ x $40 \mathrm{~cm}$ sedalam $40 \mathrm{~cm}$ pada lahan yang akan ditanami. Pembuatan lubang tanam dilakukan secara manual menggunakan cangkul. Tidak jauh dari lubang tanam ditancapkan sebanyak 4 tonggak kayu 
yang memiliki panjang $\pm 2 \mathrm{~m}$ dengan jarak sekitar 100 $\mathrm{cm}$ x $100 \mathrm{~cm}$ dari tanaman aren dan pada bagian atasnya diberi paranet $75 \%$ serta ditiap ketiga sisi pada ketiga tonggak kayu diberi naungan berupa paranet $75 \%$ atau pelepah kelapa sawit.

\section{Penanaman bibit aren}

Penanaman bibit aren dilakukan dengan cara ditanam di tengah lubang tanam dengan kondisi polibag telah terbuka dan ditimbun mencapai leher akar dengan menggunakan tanah bekas galian tadi, kemudian tanah dipadatkan. Pemberian kompos tandan kosong kelapa sawit (TKKS) sebanyak $5 \mathrm{~kg}$ lubang $\operatorname{tanam}^{-1}$ dan perlakuan pengapuran $\left(30,60,120 \mathrm{~g}_{\text {tanaman }}{ }^{-1}\right)$ diberikan pada saat penanaman. Adapun hasil analisis kompos TKKS yaitu kadar air $81.33 \%$, kadar abu $16.91 \%$, kadar bahan organik $75.54 \%, \mathrm{pH} 7, \mathrm{C}$-organik $33.61 \%$, N 2.72\% dan rasio C/N 12.36\%. Sebelumnya inokulasi mikoriza telah dilakukan terlebih dahulu oleh Miska (2015), dimana inokulasi mikoriza dilakukan ketika biji aren berkecambah sekitar umur 120 hari setelah tanam (HST) yaitu ketika telah terbentuknya daun pertama kecambah aren. Dosis inokulum FMA indigenous dan FMA mycofer yang diberikan yaitu 50 g.

\section{Pemeliharaan}

Pemeliharaan meliputi penyiraman dengan menggunakan truk tangki air yang dilakukan 2 kali dalam seminggu jika hujan tidak kunjung turun. Namun, jika hujan maka penyiraman tidak perlu dilakukan. Pengendalian gulma dilakukan apabila ada gulma yang berada di sekitar tanaman aren. Pengendalian gulma bisa dilakukan secara manual dengan mencabuti rerumputan dengan tangan ataupun menggunakan sabit.

\section{Pengambilan contoh tanah dan akar untuk identifikasi spora dan kolonisasi}

Pengamatan pertumbuhan tanaman aren di lahan pasca tambang berakhir pada 12 MST yang dilanjutkan dengan pengambilan contoh tanah dan akar. Pengambilan contoh tanah dan akar dapat dilakukan secara bersamaan dengan mendongkel akar beserta tanah tersebut menggunakan pisau belati. Tanah yang diambil sebanyak $50 \mathrm{~g}$, sedangkan untuk akar diambil pada akar-akar muda yang halus dari tiap tanaman aren. Setiap pengambilan contoh tanah dan akar lalu dimasukkan ke dalam kantong plastik ang pada bagian luar telah diberi label nama sesuai perlakuan. Kantong plastik dibiarkan terbuka selama \pm 10 menit supaya contoh tanah yang diambil respirasinya berkurang dan telah cukup dingin. Jika contoh tanah belum langsung diamati, maka disimpan ke dalam lemari pendingin dengan suhu $6^{\circ}$, sedangkan untuk akar dicuci bersih terlebih dahulu kemudian disimpan dalam larutan FAA (Formalin + aseton + alkohol $50 \%$ (nisbah 90:5:5)) (Nusantara et al. 2012).

\section{Pengamatan kolonisasi akar}

Pengamatan terhadap pewarnaan akar mengacu pada metode Philips dan Hayman (1970) dilakukan pada akhir penelitian. Akar yang diambil adalah akarakar muda yang masih kecil dan halus. Akar-akar tersebut dicuci bersih menggunakan air destilata. Setelah akar tersebut bersih kemudian dipotong-potong sepanjang $1 \mathrm{~cm}$. Setelah itu, akar direndam dalam $\mathrm{KOH}$ $10 \%$ selama 1 hari kemudian dipanaskan 5 menit. Larutan $\mathrm{KOH} 10 \%$ tersebut dibuang kemudian akar dicuci menggunakan air dan selanjutnya merendam akar tersebut ke dalam larutan $\mathrm{HCl} 2 \%$ selama 1 hari lalu kembali dipanaskan setelah 5 menit. Larutan $\mathrm{HCl} 2 \%$ tersebut dibuang dan tanpa dicuci lalu memasukkan akar kedalam larutan trypan blue selama 1 hari lalu dipanaskan 5 menit. Setelah 1 hari, larutan trypan blue dibuang kemudian merendam akar ke dalam larutan destaining. Setelah direndam dalam larutan destaining, kemudian menyusun 10 potong akar pada kaca preparat, lalu menutupnya dengan 2 kaca penutup pada tiap 5 potongan akar. Tahap selanjutnya yaitu mengamati preparat di bawah mikroskop dan menghitung berapa persen jumlah akar yang terkolonisasi FMA. Kolonisasi dapat dilihat melalui adanya vesikula, arbuskula, hifa maupun spora yang mengkolonisasi akar. Perhitungan kolonisasi akar menggunakan rumus Brundrett et al. (1996), yaitu :

\section{$\%$ - Kolonisasi akar oleh FMA \\ $=\frac{\text { jumlah bidang pandang yang terkolonisasi FMA }}{\text { jumlah keseluruhan bidang pandang }} \times 100 \%$}

\section{Identifikasi spora}

Identifikasi spora dilakukan secara deskriptif. Teknik sieving mengacu pada laboratorium Silvikultur SEAMEO BIOTROP. Contoh tanah sebanyak $10 \mathrm{~g}$ ditimbang dengan menggunakan timbangan. Kemudian memasukkan tanah ke dalam gelas ukur dan menambahkan sebanyak $50 \mathrm{~mL}$ air sambil diaduk. Setelah tercampur, kemudian menuangkan larutan tersebut kedalam saringan spora 4 tingkat dengan ukuran $425 \mu \mathrm{m}, 212 \mu \mathrm{m}, 106$ dan $63 \mu \mathrm{m}$ di bawah air mengalir. Kemudian memasukkan hasil penyaringan dari saringan bertingkat $212 \mu \mathrm{m}, 106 \mu \mathrm{m}$ dan $63 \mu \mathrm{m}$ ke dalam $1 / 3$ tabung dan menambahkan larutan glukosa $60 \%$ hingga penuh. Setelah tabung tersebut terisi, lalu memasukkan tabung-tabung tersebut ke dalam sentrifuse dengan kecepatan 3000 rpm selama 5 menit. Setelah 5 menit, mengeluarkan supernatan yang terbentuk dan menuangnya ke kertas saring lalu kertas saring berspora diletakkan pada cawan petri. Selanjutnya mengamati kertas saring berspora di bawah mikroskop binokuler, menghitung jumlah spora dan karakterisasi spora FMA. Kemudian memindahkan spora yang terdapat pada kertas saring di cawan petri ke dalam kaca preparat yang sudah ditetesi $P V L G$ maupun Melzer. Kemudian mengidentifikasi tipe spora FMA yang ditemukan. Pengidentifikasian FMA dilakukan sampai tingkat genus dengan melihat bentuk, warna, dan ukuran spora berdasarkan deskripsi morfologis genus FMA (Brundrett et al. 1996).

\section{Pengamatan}

Pengamatan dan pengukuran tanaman aren yang telah ditanam di lahan pasca tambang batubara dilakukan selama 4 bulan. Adapun variabel pengamatan yang diamati, seperti :

1. Tinggi tanaman $(\mathrm{cm})$; pengukuran menggunakan alat ukur (meteran) mulai dari pangkal batang hingga titik tumbuh yang dilakukan tiap 3 minggu sekali. 
2. Jumlah pelepah daun (helai); pelepah daun yang dihitung adalah pelepah daun yang telah membuka sempurna yang dilakukan tiap 3 minggu sekali.

3. Panjang rachis $(\mathrm{cm})$; panjang rachis diukur dari anak daun pertama sampai ujung daun yang dilakukan tiap 3 minggu sekali.

4. Diameter tanaman (mm); pengukuran diameter dilakukan pada bagian $1 \mathrm{~cm}$ dari pangkal pelepah menggunakan jangka sorong yang dilakukan tiap 3 minggu sekali.

5. Kolonisasi akar (\%); pengamatan kolonisasi akar dilakukan di akhir penelitian.

6. Identifikasi spora; pengamatan identifikasi spora dilakukan di akhir penelitian secara deskriptif. Pengidentifikasian FMA dilakukan sampai tingkat genus dengan melihat bentuk, warna, dan ukuran spora berdasarkan deskripsi morfologis genus FMA (Brundrett et al. 1996).

\section{HASIL DAN PEMBAHASAN}

\section{Karakteristik keadaan bibit aren selama di pembibitan}

Bibit aren yang telah bermikoriza ini merupakan penelitian lanjutan dari mahasiswa sebelumnya (Miska 2015). Bibit aren sebelum ditanam di lahan pasca tambang, terlebih dahulu dilakukan evaluasi terhadap pertumbuhan, identifikasi spora dan kolonisasi akar selama berada di pembibitan SEAMEO BIOTROP. Hasil penelitian bibit aren berumur 19 bulan dengan peubah pertumbuhan tanaman menunjukkan tidak berpengaruh nyata pada perlakuan pemupukan $\mathrm{P}$ dan inokulasi FMA untuk peubah tinggi tanaman, jumlah pelepah daun, panjang rachis dan diameter yang dapat dilihat pada Tabel 1. Bibit aren yang semula tanpa inokulum FMA, setelah berumur 19 bulan menjadi terinfeksi FMA sebesar $43 \%$.

Selama di pembibitan SEAMEO BIOTROP ternyata akar-akar tanaman aren sudah banyak yang keluar dari lubang-lubang polybag yang menyebabkan akar-akar yang semula tanaman kontrol menjadi terinfeksi FMA. Adapun infeksi akar pada struktur FMA terdapat pada hifa internal, hifa eksternal dan vesikula. Tipe spora FMA yang ditemukan pada tanaman aren selama pembibitan adalah Glomus sp., Acaulospora sp., dan Gigaspora sp. Diketahui bahwa perlakuan pupuk P dan FMA tidak berpengaruh nyata terhadap kolonisasi akar. Pemupukan dan FMA mycofer memiliki persen infeksi akar tertinggi sebesar $69.7 \%$ yang termasuk kategori kelas 4 menurut Rajapakse dan Miller (1992) dan kategori tinggi menurut O'Connor et al. (2001). Selain akar-akar bibit aren sudah banyak yang keluar dari lubang-lubang polibag serta polibag sudah mulai rapuh ketika dipegang, maka perlu dilapisi dengan polibag baru sebelum dibawa ke lahan pasca tambang batubara di Tanjung Enim, Sumatera Selatan.

\section{Kondisi umum lokasi percobaan}

Tanaman membutuhkan air untuk kelangsungan hidupnya, tak terkecuali dengan tanaman aren. Terlihat pada Tabel 2, pada awal penanaman sudah mulai turun hujan dengan curah hujan sebesar $494.9 \mathrm{~mm}$. Penanaman bibit aren dilakukan ketika lubang tanam selesai digali, karena jika tidak dilakukan maka lubang akan terendam dengan air hujan. Curah hujan di bulan Desember sebesar $25.2 \mathrm{~mm}$ yang berarti mengalami penurunan dari bulan November. Supaya tanaman aren tidak mati maka dilakukan penyiraman menggunakan water tank. Curah hujan kembali meningkat pada bulan Januari dan Februari dengan curah hujan sebesar 165.3 dan $521.2 \mathrm{~mm}$, kembali turun pada bulan Maret dengan curah hujan $161.2 \mathrm{~mm}$.

Tanaman aren ditanam pada lokasi lahan pasca tambang yang berada di daerah Tupak. Lahan ini dijadikan lokasi agroforestry pada tahun 2015 dengan luas lahan sekitar 20 ha yang terdiri dari 10 blok. Lokasi Tupak ini berada pada ketinggian $100 \mathrm{~m} \mathrm{dpl} \mathrm{(di} \mathrm{atas}$ permukaan laut).

\section{Hasil analisis tanah}

Sampel tanah yang dianalisis di awal penelitian merupakan sampel tanah yang belum diberikan perlakuan kompos. Setelah dilakukan analisis terhadap $\mathrm{pH}$ tanah, terjadi peningkatan $\mathrm{pH}$ di akhir penelitian yang diduga karena adanya pemberian kompos TKKS

Tabel 1 Pengaruh pupuk P dan inokulasi FMA terhadap peubah pertumbuhan bibit aren berumur 19 bulan

\begin{tabular}{lccccc}
\hline Perlakuan & $\begin{array}{c}\text { Tinggi } \\
\text { tanaman }(\mathrm{cm})\end{array}$ & $\begin{array}{c}\text { Jumlah pelepah } \\
\text { daun (helai) }\end{array}$ & $\begin{array}{c}\text { Panjang } \\
\text { rachis }(\mathrm{cm})\end{array}$ & $\begin{array}{c}\text { Diameter } \\
\text { tanaman }(\mathrm{mm})\end{array}$ & $\begin{array}{c}\text { Kolonisasi } \\
\text { mikoriza }(\%)\end{array}$ \\
\hline $\begin{array}{l}\text { Pemupukan P } \\
\text { Tanpa pemupukan P }\end{array}$ & 136.4 & 3.5 & 33.3 & 37.9 & 53.0 \\
Pemupukan P & 128.2 & 3.4 & 36.6 & 38.7 & 49.1 \\
FMA & 130.2 & 3.4 & 35.0 & 37.0 & 43.0 \\
Tanpa FMA & 127.1 & 3.5 & 34.1 & 38.2 & 45.2 \\
FMA indigenous & 139.6 & 3.5 & 35.9 & 39.8 & 64.8 \\
FMA mycofer &
\end{tabular}

Keterangan : $\mathrm{tn}=$ tidak berbeda nyata pada uji $\mathrm{F} 5 \%$

Tabel 2 Data curah hujan lokasi Tambang Air Laya (TAL) dari bulan November 2016 Maret 2017

\begin{tabular}{lccccc}
\hline Parameter & November 2016 & Desember 2016 & Januari 2017 & Februari 2017 & Maret 2017 \\
\hline $\begin{array}{l}\text { Curah hujan }(\mathrm{mm}) \\
\begin{array}{l}\text { Jumlah hari hujan } \\
\text { (hari) }\end{array}\end{array}$ & 494.9 & 25.2 & 165.3 & 521.2 & 161.2 \\
\hline
\end{tabular}


dan pengapuran. Tabel 3 memperlihatkan bahwa perlakuan kombinasi FMA indigenous dan tanpa pengapuran, FMA indigenous dan pengapuran $60 \mathrm{~g}$ tanaman $^{-1}$, serta FMA mycofer dan tanpa pengapuran memiliki $\mathrm{pH}$ di akhir penelitian yang netral, berturutturut 6.73, 7.17 dan 6.61. Hasil penelitian Megawati et al. (2014) menyebutkan bahwa penambahan kapur sebanyak 2 dan $3 \mathrm{~kg}$ lubang tanam ${ }^{-1}$ dapat menaikkan $\mathrm{pH}$ pada kisaran aman untuk pertumbuhan tanaman Acacia mangium.

Analisis sifat kimia tanah juga dilakukan pada parameter C-organik, $\mathrm{N}$-total, $\mathrm{P}$-tersedia, $\mathrm{K}$ dan rasio $\mathrm{C} / \mathrm{N}$ yang terdapat pada Tabel 3. Terjadi penurunan kadar rasio $\mathrm{C} / \mathrm{N}$ antara sesudah dan sebelum penelitian seperti terlihat pada Tabel 3. Penurunan kadar rasio $\mathrm{C} / \mathrm{N}$ ini dikarenakan adanya dekomposisi dari kompos TKKS yang diberikan pada lubang tanam, hal ini sejalan dengan hasil penelitian Margarettha (2010) yang menyebutkan bahwa turunnya kadar rasio $\mathrm{C} / \mathrm{N}$ mengindikasikan bahwa bahan organik pada media tanam telah terjadi proses dekomposisi yang akan menghasilkan asam-asam organik.

Kompos Tandan Kosong Kelapa Sawit (TKKS) diberikan bukan sebagai perlakuan dalam penelitian ini.
Kompos TKKS merupakan limbah padat hasil pabrik kelapa sawit yang jumlahnya cukup besar, yaitu sekitar 6 juta ton per tahun. Kompos TKKS diperoleh dari anak perusahaan PTBA yaitu PT Bumi Sawindo Permai (BSP). Menurut Purnamayanti (2013), kompos TKKS yang digunakan sebagai bahan organik adalah kompos TKKS yang berumur 4 bulan. Semakin lama waktu pengomposan TKKS, maka kompos yang dihasilkan akan semakin baik. Ciri-ciri kompos yang sudah matang yaitu berwarna menjadi coklat kehitaman dan jika diremas TKKS mudah putus serat-seratnya.

\section{Karakteristik pertumbuhan yang diamati}

Pertumbuhan merupakan suatu proses pertambahan ukuran, baik volume, bobot dan jumlah sel yang bersifat irreversible yang berarti terjadinya peningkatan pertambahan jumlah sel atau pun bertambahnya jumlah dan dimensi tanaman (Salisbury \& Ross 1995). Karakteristik pertumbuhan yang diamati meliputi tinggi tanaman, jumlah pelepah daun, panjang rachis, dan diameter. Hasil sidik ragam pengaruh perlakuan kombinasi FMA dan pengapuran terhadap peubah yang diamati terdapat pada Tabel 4. Terlihat pada Tabel 4 bahwa perlakuan kombinasi FMA dan pengapuran tidak

Tabel 3 Analisis sifat kimia tanah di awal dan akhir penelitian

\begin{tabular}{|c|c|c|c|c|c|c|c|}
\hline $\begin{array}{l}\text { Sifat kimia } \\
\text { tanah }\end{array}$ & $\begin{array}{l}\text { Awal } \\
\text { peneltian }\end{array}$ & MaK0 & MaK1 & $\begin{array}{l}\text { MiKo } \\
\text { (Akhir Pe }\end{array}$ & $\begin{array}{r}\text { MiK2 } \\
\text { elitian) }\end{array}$ & MmK0 & MmK3 \\
\hline C-organik (\%) & $2.42(\mathrm{~S})$ & $2.49(\mathrm{~S})$ & $2.22(\mathrm{~S})$ & $2.99(\mathrm{~S})$ & $2.51(\mathrm{~S})$ & $2.83(\mathrm{~S})$ & $2.87(\mathrm{~S})$ \\
\hline N-total $(\%)$ & 0.08 (SR) & $0.12(\mathrm{R})$ & $0.10(\mathrm{R})$ & $0.14(\mathrm{R})$ & $0.12(\mathrm{R})$ & $0.13(\mathrm{R})$ & $0.14(\mathrm{R})$ \\
\hline $\begin{array}{l}\text { P-tersedia } \\
\text { (ppm) }\end{array}$ & 1.48 (SR) & 3.68 (SR) & $16.33(\mathrm{~T})$ & 3.49 (SR) & $2.56(\mathrm{SR})$ & 4.89 (SR) & $8.09(\mathrm{R})$ \\
\hline $\mathrm{K}(\mathrm{Mg} / 100 \mathrm{~g})$ & $55.17(\mathrm{~T})$ & $96.24(\mathrm{ST})$ & $71.06(\mathrm{ST})$ & $75.29(\mathrm{ST})$ & $81.40(\mathrm{ST})$ & $46.24(\mathrm{~T})$ & $51.43(\mathrm{~T})$ \\
\hline rasio $\mathrm{C} / \mathrm{N}$ & 32.03 (ST) & $21.17(\mathrm{~T})$ & $21.79(\mathrm{~T})$ & $21.70(\mathrm{~T})$ & $20.46(\mathrm{~T})$ & $22.67(\mathrm{~T})$ & $20.04(\mathrm{~T})$ \\
\hline $\mathrm{pH}$ & - & $5.59(\mathrm{AM})$ & $6.45(\mathrm{AM})$ & $6.73(\mathrm{~N})$ & $7.17(\mathrm{~N})$ & $6.61(\mathrm{~N})$ & $6.53(\mathrm{AM})$ \\
\hline MaK0 & $4.8 \quad(\mathrm{M})$ & & & & & & \\
\hline MaK1 & $5.8 \quad(\mathrm{M})$ & & & & & & \\
\hline MiK0 & $5.8 \quad(\mathrm{M})$ & & & & & & \\
\hline MiK2 & $6.1(\mathrm{AM})$ & & & & & & \\
\hline MmK0 & $5.5 \quad(\mathrm{M})$ & & & & & & \\
\hline MmK3 & $6.0(\mathrm{AM})$ & & & & & & \\
\hline Keterangan : H & $\begin{array}{l}\text { analisis tanah } \\
\text { hia tanah.; Ma } \\
\text { mikoriza tanpa } \\
\text { pa pengapuran } \\
\text { kulasi FMA m } \text { aman }^{-1} ;(\mathrm{SR})=\end{array}$ & $\begin{array}{l}\text { Laboratoriu } \\
=\text { bibit be } \\
\text { inokulasi da } \\
\text { liK2 = bibit } \\
\text { fer dan tanp }\end{array}$ & $\begin{array}{l}\text { engujian Air, } \\
\text { oriza tanpa } \\
\text { engapuran } 30 \\
\text { kulasi FMA } \\
\text { engapuran, }\end{array}$ & $\begin{array}{l}\text { nnah dan Batu } \\
\text { nokulasi dan } \\
\text { tanaman }{ }^{-1}, \mathrm{~N} \\
\text { digenous dan } \\
\text { K3 = bibit in }\end{array}$ & $\begin{array}{l}\text { PTBA; ber } \\
\text { mpa pengap } \\
\text { K0 = bibit } \\
\text { engapuran } 6 \\
\text { ulasi FMA }\end{array}$ & $\begin{array}{l}\text { rkan kriteri } \\
\text { (kontrol), } \\
\text { ulasi FMA } \\
\text { tanaman }{ }^{-1} \text {, } \\
\text { ofer dan per }\end{array}$ & $\begin{array}{l}\text { penilaian sifat } \\
\text { MaK1 = bibit } \\
\text { ndigenous dan } \\
\text { MmK0 = bibit } \\
\text { gapuran } 120 \mathrm{~g} \\
\text { i. }\end{array}$ \\
\hline
\end{tabular}

Tabel 4 Rekapitulasi hasil sidik ragam perlakuan kombinasi FMA dan pengapuran terhadap peubah yang diamati pada bibit aren di lahan pasca tambang

\begin{tabular}{lccc}
\hline \multicolumn{1}{c}{ Peubah } & FMA $(\mathrm{F})$ & Pengapuran $(\mathrm{P})$ & F x P \\
\hline Tinggi tanaman $(\mathrm{cm})$ & tn & tn & tn \\
Jumlah pelepah daun (helai) & tn & tn & tn \\
Panjang rachis $(\mathrm{cm})$ & tn & tn & tn \\
Diameter $(\mathrm{mm})$ & tn & tn & tn \\
Jumlah spora & tn & tn & tn \\
Kolonisasi akar $(\%)$ & tn & tn & tn \\
\hline
\end{tabular}

Keterangan : tn $=p>0.05$ 
berpengaruh nyata terhadap semua peubah pertumbuhan yaitu tinggi tanaman, jumlah pelepah daun, panjang rachis, dan diameter.

Peubah pertumbuhan seperti tinggi dan diameter memiliki pertambahan tinggi yang terus meningkat di tiap 3 minggu pengamatan. Jika pengamatan pertumbuhan terus dilanjutkan maka diperkirakan akan membentuk kurva sigmoid yang pada awalnya lambat tapi kemudian terus meningkat. Adapun respon pertumbuhan aren ketika ditanam di lahan pasca tambang seperti terlihat pada Gambar 1 dan Gambar 2.

Selama 4 bulan ditanam di lahan pasca tambang, perlakuan kombinasi FMA dan pengapuran tidak berpengaruh nyata terhadap peubah pertumbuhan baik tinggi tanaman, diameter, panjang rachis dan jumlah pelepah daun. Tidak terlihat perbedaan pertambahan tinggi tanaman dari masing-masing perlakuan kombinasi. Hal ini diduga karena pengamatan yang masih terlalu singkat sehingga pengaruh perlakuan kombinasi FMA dan pengapuran belum terlihat.

Seperti diketahui bahwa tanaman aren termasuk tanaman yang pertumbuhannya lambat seperti pada pelepah daun yang memiliki pertambahan tiap tahun hanya sekitar 3-6 helai pelepah (Smits 1996). Berbeda halnya dengan jenis famili Arecaceae lainnya, seperti kelapa yang menghasilkan pelepah daun 1 helai tiap bulan dan kelapa sawit untuk bibit yang berumur 5 atau 6 tahun menghasilkan jumlah pelepah daun tiap tahun sebanyak 30-40 helai, setelah itu akan menurun menjadi 20-25 helai pelepah daun tiap tahunnya (Hartley 1997). Selain itu, pertumbuhan tanaman juga dipengaruhi faktor genetik dan lingkungan. Faktor genetik berasal dari bibit aren itu sendiri, sedangkan faktor lingkungan seperti teknik budidaya, curah hujan, dan suhu.

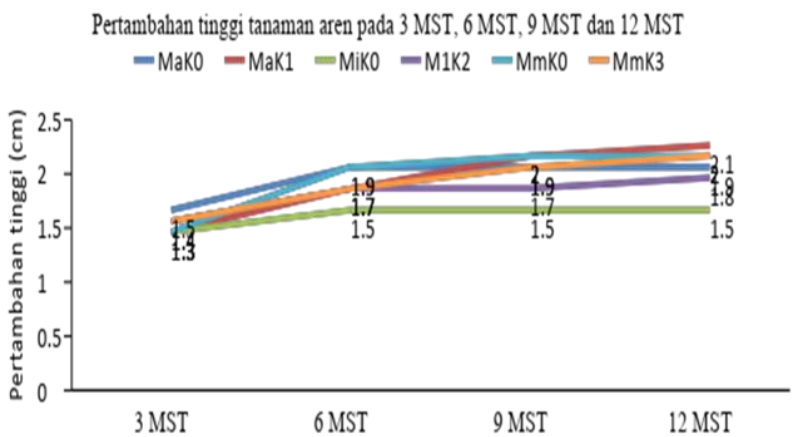

Gambar 1 Grafik pertambahan tinggi tanaman aren pada 3 MST, 6 MST, 9 MST dan 12 MST. MST = Masa Setelah Tanam

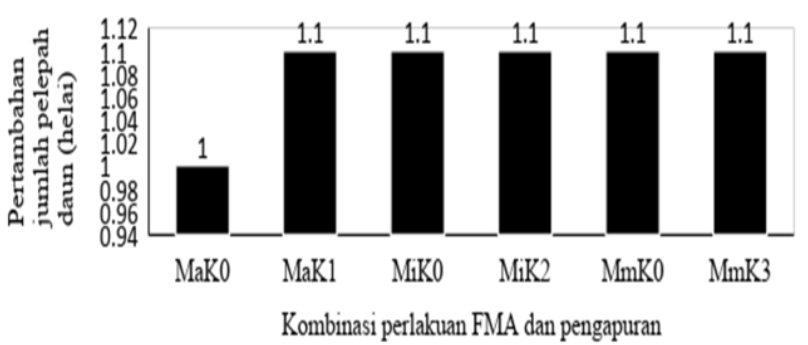

Gambar 3 diagram pertambahan jumlah pelepah daun (helai)

\section{Kolonisasi akar}

Perlakuan kombinasi FMA dan pengapuran tidak berpengaruh nyata terhadap kolonisasi akar. Gambar 5 menunjukkan kolonisasi akar oleh FMA pada perlakuan kombinasi FMA dan pengapuran. Ada atau tidaknya infeksi pada akar tanaman dapat dilihat dari asosiasi antara FMA dengan tanaman itu sendiri. Data dari hasil pengamatan yang diperoleh, seluruh tanaman yang terdapat pada perlakuan kombinasi FMA dan pengapuran telah terinfeksi. Secara umum, besarnya infeksi yang terjadi pada akar tanaman aren dikategorikan termasuk kelas 3 (26.9-46.4\%) menurut Rajapakse dan Miller (1992), serta tergolong sedang $(10-30 \%)$ dan tinggi $(>30 \%)$ berdasarkan kriteria O’Connor et al. (2001).

Kandungan P-tersedia yang tinggi pada perlakuan kombinasi bibit bermikoriza tanpa diinokulasi dan pengapuran $30 \mathrm{~g}$ tanaman $^{-1}$ sebesar $16.33 \mathrm{ppm}$ (Tabel 3) menyebabkan kolonisasi akar oleh FMA yang lebih rendah (26.9\%) dibandingkan dengan perlakuan lainnya. Nilai $\mathrm{P}$ tersebut tidak menghambat kolonisasi karena hambatan biasanya terjadi pada $\mathrm{P} \geq 50 \mathrm{ppm}$. Nilai P-tersedia pada bibit inokulasi FMA indigenous dan pengapuran $60 \mathrm{~g}$ tanaman $^{-1}$ sebesar $2.56 \mathrm{ppm}$ memiliki kolonisasi akar yang lebih besar $(46.4 \%)$ dibandingkan perlakuan lainnya, karena $\mathrm{P}$ yang tersedia di tanah dalam jumlah yang tinggi akan secara langsung menurunkan aktivitas FMA sehingga terjadi pengurangan keberadaan FMA di tanah. Hal ini sesuai dengan hasil penelitian Pulungan (2013) yang menyatakan ketersediaan unsur hara pada tanah tempat tumbuhnya tanaman akan mempengaruhi akar tanaman yang terinfeksi FMA.

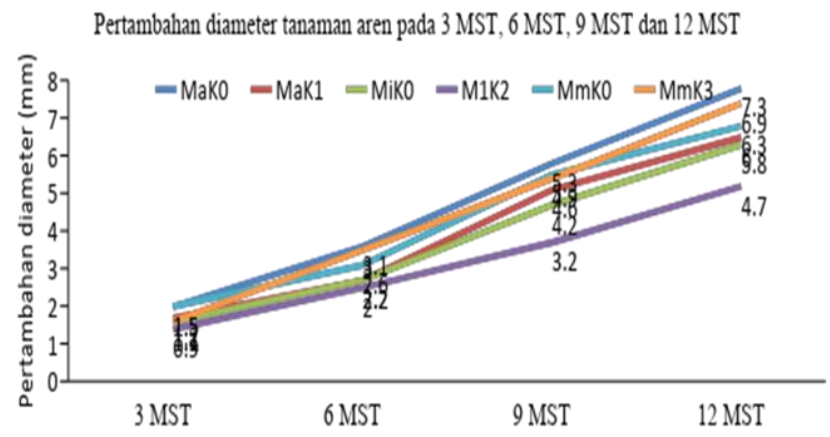

Gambar 2 Grafik pertambahan diameter tanaman aren pada 3 MST, 6 MST, 9 MST dan 12 MST. MST $=$ Masa Setelah Tanam

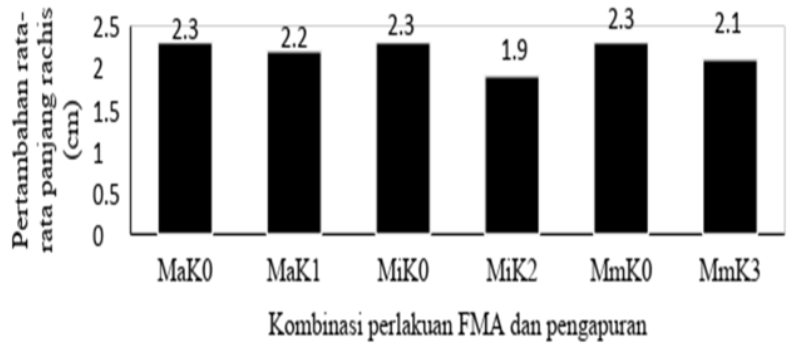

Gambar 4 diagram pertambahan rata-rata panjang rachis (cm) 
Penelitian ini menemukan bahwa infeksi akar pada struktur FMA terdapat pada hifa dan vesikula sama seperti halnya ketika evaluasi bibit aren berumur 19 bulan sewaktu berada di pembibitan. Hifa merupakan benang-benang halus yang digunakan untuk translokasi unsur hara (hifa internal) dan membantu proses penyerapan air dan unsur hara (hifa eksternal). Vesikula terbentuk dari hifa internal yang menggelembung berbentuk seperti globose yang berfungsi sebagai tempat cadangan makanan (Smith \& Read 1997).

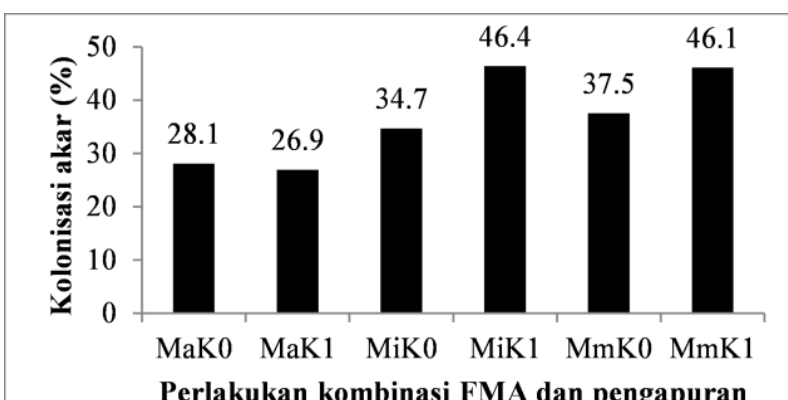

Gambar 5 Diagram kolonisasi akar oleh FMA tanaman aren di lahan pasca tambang pada setiap perlakuan kombinasi FMA dan pengapuran. MaK0 = bibit bermikoriza tanpa diinokulasi dan tanpa pengapuran (kontrol), MaK1 = bibit bermikoriza tanpa diinokulasi dan pengapuran $30 \mathrm{~g} \operatorname{tanaman}^{-1}$, MiK0 = bibit inokulasi FMA indigenous dan tanpa pengapuran, MiK2 = bibit inokulasi FMA indigenous dan pengapuran $60 \mathrm{~g}$ tanaman $^{-1}$, MmK0 = bibit inokulasi FMA mycofer dan tanpa pengapuran, $\mathrm{MmK} 3$ = bibit inokulasi FMA mycofer dan pengapuran $120 \mathrm{~g}$ $\operatorname{tanaman}^{-1}$

\section{Genus spora yang ditemukan}

Perlakuan kombinasi FMA dan pengapuran tidak berpengaruh nyata terhadap jumlah spora. Tipe spora FMA yang diamati pada penelitian ini hanya sampai tingkat genus. Data hasil pengamatan yang didapat menunjukkan adanya 3 genus yang ditemukan yaitu Glomus sp., Gigaspora sp. dan Acaulospora sp. Hal ini serupa dengan hasil penelitian Ulfa et al. (2011) yang menyebutkan bahwa pada semua lokasi areal bekas tambang batubara ditemukan 3 genus spora yaitu Acaulospora sp dan Gigaspora sp. terdapat pada semua lokasi, sedangkan Glomus sp. ditemukan pada tanah yang timbunan yang berumur 8 tahun.

Genus spora yang ditemukan merupakan spora yang berasal dari FMA indigenous dan FMA Mycofer yang sama dengan hasil penelitian dari Miska (2015) maupun pada bibit tanaman aren yang berumur 19 bulan ketika berada di pembibitan dan terbawa pada saat penanaman bibit di lahan pasca tambang batubara. Menurut Setiadi dan Setiawan (2011), jenis FMA yang terdapat pada lahan bekas tambang dapat dimanfaatkan sebagai sumber inokulum, karena FMA dapat meningkatkan daya hidup dan pertumbuhan tanaman. Hasil penelitian juga menunjukkan terdapat beberapa jenis spesies yang berbeda dalam satu genus FMA, seperti yang terlihat pada Tabel 5 .

\section{Kepadatan spora}

Kepadatan spora yang ditemukan pada tiap perlakuan kombinasi FMA dan pengapuran dapat dilihat pada Gambar 7. Kepadatan spora paling banyak ditemukan pada bibit inokulasi FMA indigenous dan pengapuran $60 \mathrm{~g} \operatorname{tanaman}^{-1}$ sebanyak 48 spora $10 \mathrm{~g}^{-1}$ tanah dan kepadatan spora paling sedikit terdapat pada bibit bermikoriza tanpa diinokulasi dan tanpa pengapuran dengan jumlah spora sebanyak 15 spora 10 $\mathrm{g}^{-1}$ tanah. Hal ini sesuai dengan Delvian (2008) yang menyatakan bahwa jumlah kandungan P-tersedia yang rendah mampu meningkatkan jumlah spora yaitu pada bibit inokulasi FMA indigenous dan pengapuran $60 \mathrm{~g}$ $\operatorname{tanaman}^{-1}$

Tabel 5 Tipe genus spora FMA yang terdapat pada perlakuan kombinasi FMA dan pengapuran tanaman aren di lahan pasca tambang

\begin{tabular}{|c|c|c|c|c|c|c|}
\hline Tipe spora & MaK0 & MaK1 & MiK0 & MiK2 & MmK0 & $\mathrm{MmK} 3$ \\
\hline Glomus sp.1 & $\mathrm{v}$ & $\mathrm{V}$ & $\mathrm{V}$ & $\mathrm{v}$ & $\mathrm{v}$ & $\mathrm{v}$ \\
\hline Glomus sp.2 & $\mathrm{v}$ & $\mathrm{v}$ & $\mathrm{v}$ & $\mathrm{v}$ & & $\mathrm{v}$ \\
\hline Glomus sp.3 & $\mathrm{V}$ & & & $\mathrm{v}$ & $\mathrm{V}$ & \\
\hline Glomus sp.4 & $\mathrm{v}$ & & & & & $\mathrm{v}$ \\
\hline Glomus sp.5 & & $\mathrm{V}$ & $\mathrm{V}$ & $\mathrm{v}$ & $\mathrm{V}$ & $\mathrm{v}$ \\
\hline Glomus sp.6 & & $\mathrm{v}$ & $\mathrm{v}$ & $\mathrm{v}$ & & \\
\hline Glomus sp.7 & $\mathrm{v}$ & $\mathrm{v}$ & $\mathrm{v}$ & $\mathrm{v}$ & $\mathrm{v}$ & $\mathrm{v}$ \\
\hline Glomus sp.8 & & $\mathrm{v}$ & $\mathrm{v}$ & & & $\mathrm{v}$ \\
\hline Acaulospora sp.1 & & & $\mathrm{v}$ & $\mathrm{v}$ & & $\mathrm{v}$ \\
\hline Acaulospora sp.2 & & & & & $\mathrm{v}$ & $\mathrm{v}$ \\
\hline Gigaspora sp.1 & & & & $\mathrm{v}$ & $\mathrm{v}$ & $\mathrm{v}$ \\
\hline Gigaspora sp.2 & & $\mathrm{v}$ & & & & \\
\hline Gigaspora sp.3 & & & $\mathrm{V}$ & $\mathrm{V}$ & $\mathrm{V}$ & $\mathrm{v}$ \\
\hline
\end{tabular}

Keterangan : $\quad \mathrm{v}=$ ada; MaK0 = bibit bermikoriza tanpa diinokulasi dan tanpa pengapuran (kontrol), MaK1 = bibit bermikoriza tanpa diinokulasi dan pengapuran $30 \mathrm{~g} \mathrm{tanaman}^{-1}$, MiK0 = bibit inokulasi FMA indigenous dan tanpa pengapuran, MiK2 = bibit inokulasi FMA indigenous dan pengapuran $60 \mathrm{~g}$ $\operatorname{tanaman}^{-1}, \mathrm{MmK} 0=$ bibit inokulasi FMA mycofer dan tanpa pengapuran, MmK3 = bibit inokulasi FMA mycofer dan pengapuran $120 \mathrm{~g} \operatorname{tanaman}^{-1}$. 


\section{SIMPULAN DAN SARAN}

\section{Simpulan}

Bibit aren yang awalnya tidak bermikoriza, setelah berumur 19 bulan menjadi terinfeksi FMA. Bibit aren bermikoriza ketika ditanam di lahan pasca tambang dapat tumbuh dan memberikan respon yang baik walaupun proses pertambahan peubah pertumbuhannya relatif lambat. Perlakuan kombinasi FMA dan pengapuran tidak berpengaruh nyata terhadap semua peubah yaitu tinggi tanaman, jumlah pelepah daun, panjang rachis, diameter, kolonisasi akar dan jumlah spora. Bibit aren yang ditanam di lahan pasca tambang dapat memberikan respon pertumbuhan yang baik walaupun pada perlakuan tanpa pengapuran.

\section{Saran}

Perlu dibandingkan kondisi bibit aren yang terinfeksi FMA dengan bibit aren yang benar-benar tanpa FMA untuk mengetahui efektivitas keberadaan FMA dan perlu waktu yang lebih lama lagi untuk mengetahui parameter pertumbuhan aren, kolonisasi akar, dan jumlah spora.

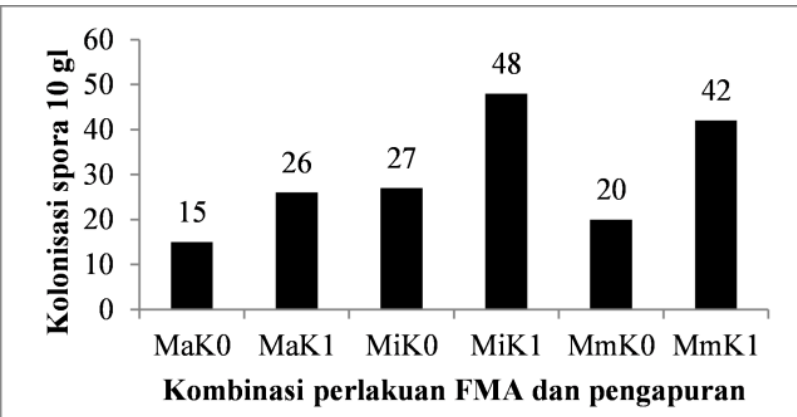

Gambar 7 Diagram rata-rata kepadatan spora $10 \mathrm{~g}^{-1}$ tanah. $\mathrm{MaK} 0=$ bibit bermikoriza tanpa diinokulasi dan tanpa pengapuran (kontrol), MaK1 = bibit bermikoriza tanpa diinokulasi dan pengapuran $30 \mathrm{~g}^{\operatorname{tanaman}^{-1}}, \mathrm{MiK} 0=$ bibit inokulasi FMA indigenous dan tanpa pengapuran, MiK2 = bibit inokulasi FMA indigenous dan pengapuran $60 \mathrm{~g}$ tanaman $^{-1}$, MmK0 = bibit inokulasi FMA mycofer dan tanpa pengapuran, MmK3 = bibit inokulasi FMA mycofer dan pengapuran $120 \mathrm{~g}$ $\operatorname{tanaman}^{-1}$

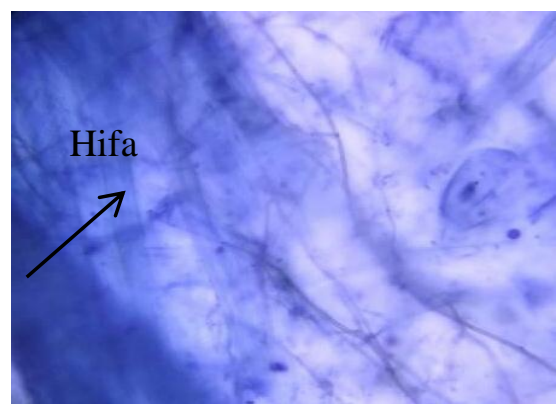

\section{UCAPAN TERIMA KASIH}

Penulis mengucapkan terima kasih yang sebesarbesarnya dan penghargaan yang setinggi-tingginya kepada Global Innovation Initiative (GII), PT. Bukit Asam (PTBA) dan SEAMEO BIOTROP yang telah memfasilitasi pelaksanaan penelitian ini.

\section{DAFTAR PUSTAKA}

Akuba RH. 2004. Profil aren. Prosiding seminar nasional aren; 2004 Juni 09; Tondano, Sulawesi Utara, Indonesia.

Brundrett M, Bougher N, Dell B, Grove T, Malajczuk N. 1996. Working with Mychorrizas In Forestry and Agriculture. Canberra (AU): Australian Centre for International Agricultural Research.

Delvian. 2008. Pengaruh spesies inang dan sumber nutrisi terhadap produksi spora fungi mikoriza arbuskular. J Natur Indonesia. 10(2): 70-72.

Effendi DS. 2010. Prospek pengembangan tanaman aren (Arrenga pinnata Merr) mendukung kebutuhan bioetanol di Indonesia. J Perspektif. 9(1): 36-46.

Hartley CWS. 1977. The oil palm. New York (US): Longman Inc.

Hermawan B. 2002. Buku Ajar Dasar-dasar Fisika Tanah. Bengkulu (ID): Lemlit UNIB Press.

Mansur I. 2010. Teknik Silvikultur untuk Reklamasi Lahan Bekas Tambang. Bogor (ID): SEAMEO BIOTROP.

Margarettha. 2010. Pemanfaatan tanah bekas tambang batubara dengan pupuk hayati mikoriza sebagai media tanam jagung manis. J. Hidrolitan. 1(3): 110.

Mariati R. 2013. Potensi produksi dan prospek pengembangan tanaman aren (Arenga pinnata MERR) di Kalimantan Timur. J AGRIFOR. 12(2): 196-205.

Megawati NJ, Wasis B, Setiadi W. 2014. Respon pertumbuhan Acacia mangium WILLD. terhadap penambahan kapur dan HSC (Humic Substances Complex) pada lahan pasca tambang batubara. $J$ Silvikultur Tropika. 5(3): 143-148.

Miska MEE. 2015. Respon pertumbuhan bibit aren (Arenga pinnata (Wurmb) Merr.) terhadap inokulasi Fungi Mikoriza Arbuskula indigeneous [tesis]. Bogor (ID): Institut Pertanian Bogor.

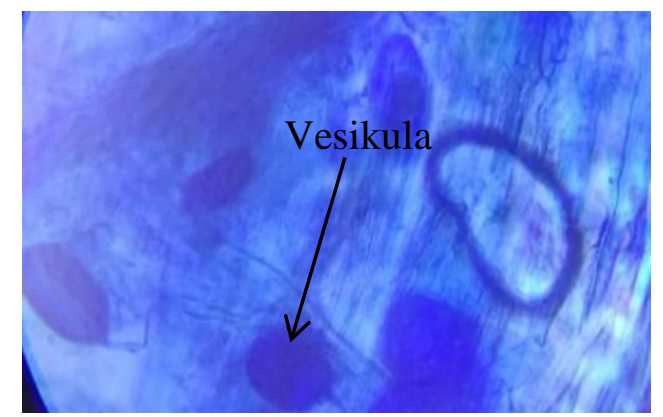

Gambar 6 Akar aren yang terinfeksi FMA di lahan pasca tambang; hifa (kiri) dan vesikula (kanan) dengan pembesaran $40 \mathrm{x}$ 
Nusantara AD, Bertham YH, Mansur I. 2012. Bekerja dengan Fungi Mikoriza Arbuskula. Bogor (ID): IPB Press.

O'Connor PJ, Smith SE, Smith FA. 2001. Arbuscular mycorrhizal associations in the southern Souther Simpson desert. Aust J Bot. 49: 493-499.

[Permentan] Peraturan Menteri Pertanian Republik Indonesia Nomor 133 Tahun 2014 tentang Pedoman Budidaya Aren (Arrenga pinnata MERR) yang Baik. Jakarta (ID).

Phillips JM, Hayman DS. 1970. Improved procedures for clearing roots and staining parasitic and vesicular-arbuscular mychorizal fungi for rapid assessment of infection. Transact Brit Mycol Soc. 55:158-161.

Pulungan ASS. 2013. Infeksi fungi mikoriza arbuskula pada akar tanaman tebu (Saccharum officinarum L). J Biosains Unimed. 1(1): 43-46.

Purnamayanti R. 2013. Teknologi pembuatan kompos tandan kosong kelapa sawit. Balai Pengkajian Teknologi Pertanian (BPTP) Jambi.

Rajapakse S, Miller JC. 1992. Methods for studying vesicular-arbuscular mycorrhizal root colonization and related root physical properties. Norris JR, Read DJ, dan Varma AK, editor. Sandiego (US): Academic Pr.
Salisbury FB, Ross CW. 1995. Fisiologi Tumbuhan. Jilid 3. Bandung (ID): Penerbit ITB.

Setiadi Y, Setiawan A. 2011. Studi status fungi mikoriza arbuskula di areal rehabilitasi pasca penambangan nikel (studi kasus PT INCO Tbk. Sorowako, Sulawesi Selatan). J Silvikultur Tropika. 3(1): 88-95.

Smits WTM. 1996. Arenga pinnata (Wurmb) Merrill. Flach M dan Rumawas F, editor. Bogor (ID): Prosea Foundation.

Smith SE, Read DJ. 2008. Mycorrhizal Symbiosis. Third edition. New York (US): Academic Press.

Suharno, Sancayaningsih RP. 2013. Fungi Mikoriza Arbuskula: potensi teknologi mikroremediasi logam berat dalam rehabilitasi lahan tambang. Bioteknologi. 10(1): 31-42.

Ulfa M, Kurniawan A, Sumardi, Sitepu I. 2011. Populasi fungi mikoriza arbuskula (FMA) lokal pada lahan pasca tambang batubara. J Penelitian Hutan dan Konservasi Alam. 8(3): 301-309.

Wicaksono AP, Mansur I. 2014. Respon pertumbuhan tanaman jabon (Anthocephalus cadamba (Roxb.) Miq) terhadap pemupukan dan pengapuran di areal bekas tambang. J Silvikultur Tropika. 5(3): 181187. 